\title{
Revista Española de Podología indexada en el Directory of Open Access Journals (DOAJ)
}

Revista Española de Podología indexed in Directory of Open Access Journals (DOAJ)

La Revista Española de Podología ha sido recientemente aceptada para su indexación en el Directory of Open Access Journals (DOAJ). El DOAJ es un directorio online organizado como un medio comunitario para indexar y proveer acceso a revistas científicas con alta calidad que se publican en acceso abierto y que cumplan el criterio de revisión por pares. DOAJ es un organismo independiente que fue creado en 2003 en la Universidad de Lund, Suecia, comenzando con 300 revistas en acceso abierto. Actualmente su base de datos contiene más de 12000 revistas en acceso abierto de 122 países y en 74 idiomas diferentes que cumplen con estrictos criterios de admisión y que cubren todas las áreas de ciencia, tecnología, medicina, ciencias sociales y humanidades.

Actualmente, DOAJ se ha convertido en los últimos años en un punto de referencia internacional para las búsquedas de artículos en revistas académicas de alta calidad con políticas de acceso abierto a través de su página web (https://doaj. org/). Su misión es aumentar la visibilidad, accesibilidad, reputación, uso e impacto de las revistas científicas de alta calidad, con revisión por pares, que sean en acceso abierto en todo el mundo. A su vez, DOAJ es coautor de los Princi- pios de Transparencia y Buenas Prácticas en Publicaciones Académicas (https://doaj.org/es/mejorespracticas) y la indexación de Revista Española de Podología en DOAJ obliga a la revista a seguir estos principios como condición obligatoria para mantenerse indexada. Estos principios aseguran cumplir unos criterios de calidad mundialmente aceptados para las revistas científicas.

Desde el comité editorial de Revista Española de Podología nos alegramos y nos sentimos orgullosos de ello, ya que para la inclusión en el DOAJ todas las revistas son revisadas de forma minuciosa por los editores de DOAJ, asegurando que se cumplen estos criterios de calidad establecidos. De hecho, DOAJ es usado en muchas organizaciones en todo el mundo como una guía o un sello de calidad de la revista con política de acceso abierto. Aunque todavía nos queda mucho trabajo para lograr la indexación en otras bases de datos, este es un primer paso para la revista y lo celebramos.

Un saludo,

Javier Pascual Huerta Redactor Jefe. Revista Española de Podología 